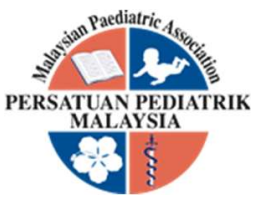

\title{
PAEDIATRIC COVID-19: REVIEW OF HOSPITAL EXPERIENCES AND IMPACT ON CHILD HEALTH SERVICES IN BANGLADESH
}

\author{
Manzoor Hussain ${ }^{1}$, Mohammad Abdullah Al Mamun², Sayeeda Anwar ${ }^{3}$, Nazma Begum $^{4}$, Abu Sayeed \\ Chowdhury ${ }^{4}$, Kamruzzaman Kamrul ${ }^{5}$
}

\begin{abstract}
Previous studies suggested that COVID-19 is more likely to infect older adults, particularly those with chronic comorbidities. However in Bangladesh, paediatric patients are on the rise. Three percent of children less than 10 years were identified as having COVID-19 infection. Though over $90 \%$ of the cases were mild or moderate in nature but many of them required hospital admission. So it appeared that local situation in Bangladesh seems to be different. This study was carried out to find out hospital experiences and impact of COVID-19 in child health in Bangladesh. Data were collected from three tertiary care hospitals of Bangladesh dealing majority of COVID-19 infected children. The hospitals were Dhaka Shishu (Children) Hospital, Dhaka Medical College Hospital and Mugda Medical College Hospital. As COVID-19 outbreak also adversely affecting different services among the children of Bangladesh, review was done to evaluate essential health delivery services especially routine immunization. Total 422 children were included from three tertiary care hospitals. They were predominantly male. Children of all age groups were infected. Significant numbers of children were admitted with moderate to severe illness (moderate $42.89 \%$, severe $35.78 \%$ and critical $16.11 \%$ ) with some casualties (mortality $4.27 \%$ ). Routine immunization has already been hampered and threatened a significant increase in child mortality due to Vaccine Preventable Disease (VPD) in coming days. Paediatric patients were on the rise and unfortunately we noticed large number of hospital admission and some casualties already. Essential health care services should be preserved to prevent avoidable losses of child lives during the COVID-19 pandemic and to protect progress in reducing child mortality achieved over recent years.
\end{abstract}

Keywords: Paediatric COVID-19, Hospital Experience, Impact on Child Health DOI: $10.51407 / \mathrm{mjpch} . v 27 i 1.121$
Received: 14 October 2020; Accepted revised manuscript: 17 May 2021

Published online: 20 June 2021

\section{Introduction}

The coronavirus disease 2019 (COVID-19) that started from China in December, 2019 caused by a novel coronavirus, severe acute respiratory syndrome-related coronavirus 2 (SARS-CoV-2) creating profound panic, fear and anxiety for human race [1-4]. On January 30, 2020, World Health Organization (WHO) declared public health emergency of international concern (PHEIC) and pandemic on 11 March 2020 [5].

A surprising feature of the disease appears, while the global coronavirus crisis worsen, that children

\footnotetext{
'Bangladesh Institute of Child Health, Dhaka Shishu (Children) Hospital, Dhaka, Bangladesh.

2Division of Neonatal Cardiology, Department of Paediatric Cardiology, Bangladesh Institute of Child Health and Dhaka Shishu (Children) Hospital, Dhaka, Bangladesh.

${ }^{3}$ Department of Paediatrics, Dhaka Medical College Hospital, Dhaka, Bangladesh.

${ }^{4}$ Department of Paediatrics, Mugda Medical College, Dhaka, Bangladesh ${ }^{5}$ Department of Paediatric Respiratory Medicine, Bangladesh Institute of Child Health and Dhaka Shishu (Children) Hospital, Dhaka, Bangladesh. Corresponding Author:

Dr. Mohammad Abdullah Al Mamun, MBBS, MD

Associate Professor, Division of Neonatal Cardiology,

Department of Paediatric Cardiology, Bangladesh Institute of

Child Health and Dhaka Shishu (Children) Hospital, Sher-e-

Bangla Nagar, Dhaka-1207, Bangladesh.

Tel.: +8801913475529 Email: mamundsh@gmail.com 
might be immune from the worst of it. Studies suggested that COVID-19 is more likely to infect older adult persons, particularly those with chronic comorbidities [6]. There is only limited data detailing the effects of COVID-19 on the paediatric population. A review of 72,314 cases by the Chinese Center for Disease Control and Prevention showed that $<1 \%$ of COVID-19 cases were in children younger than 10 years old. Children of all ages were infected, with the median age of 7 years (range 1 day to 18 years) and $56 \%$ of the infected children were males. Over $90 \%$ of the cases were mild or moderate in nature [7]. In Bangladesh $3 \%$ of children $<10$ years old were diagnosed as having COVID-19 infection [8]. Young children especially infants, however, seemed to be more susceptible to severe disease than older children; in which $10 \%$ of patients under 1 year of age had severe or critical disease [9]. In another study of 1391 children under 16 years of age assessed and tested for COVID-19, 171 children (12.3\%) were positive for SARS-CoV-2 infection. The median age of infected children was 6.7 years and $15.8 \%$ of patients had no symptoms or signs of pneumonia. Only $1.8 \%$ children required intensive care and mechanical ventilatory support, but all had pre-existing medical conditions [10].

The mechanism by which children seem less susceptible to severe infection caused by SARSCoV-2 has yet to be elucidated. It has been theorized that the ACE2 (the binding protein for SARS-CoV-2) in children is not as functional as it is in adults, and thus SARS-CoV-2 is less infectious [9].

As of 10 September, 2020, according to the Institute of Epidemiology, Disease Control and Research (IEDCR), there were 332,970 confirmed COVID-19 cases in Bangladesh, including 4,634 deaths (IFR 1.4\%) [8]. During the epidemiological week 36 (7 September, 2020), COVID-19 confirmed cases decreased by $11.6 \%$ in comparison to the previous week (14,335 and 16,224 in the previous week). The number of COVID-19 related deaths decreased by $24.8 \%$ (231 and 307 respectively) [11]. According to Director General of Health Services (DGHS) as of 31 August, there are 14,843 general beds and 550 ICU beds in Bangladesh dedicated to COVID-19. Of those $25.8 \%$ of general beds and $54.7 \%$ of ICU beds are currently occupied [12].

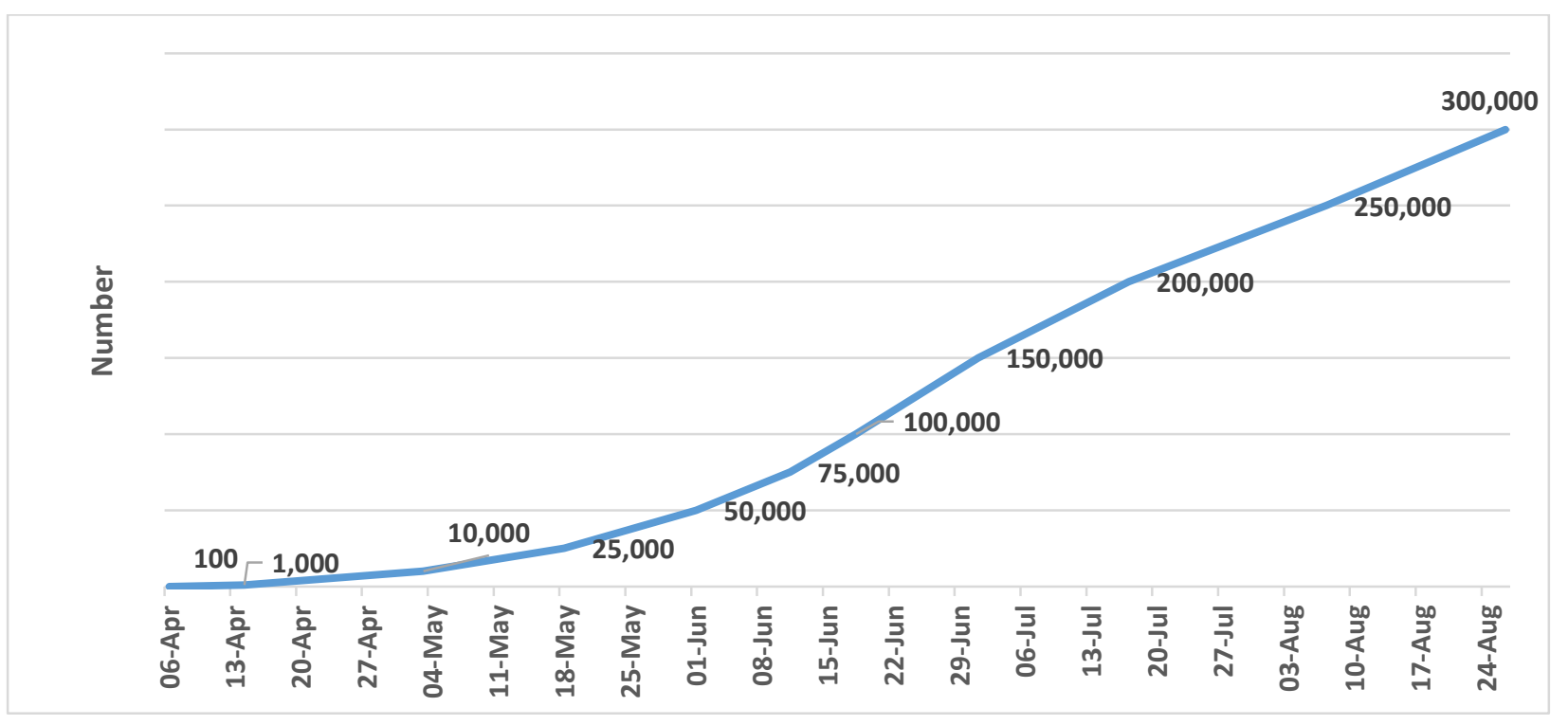

Figure 1. Landmark of COVID-19 cases in Bangladesh up to 300,000 cases [8] 


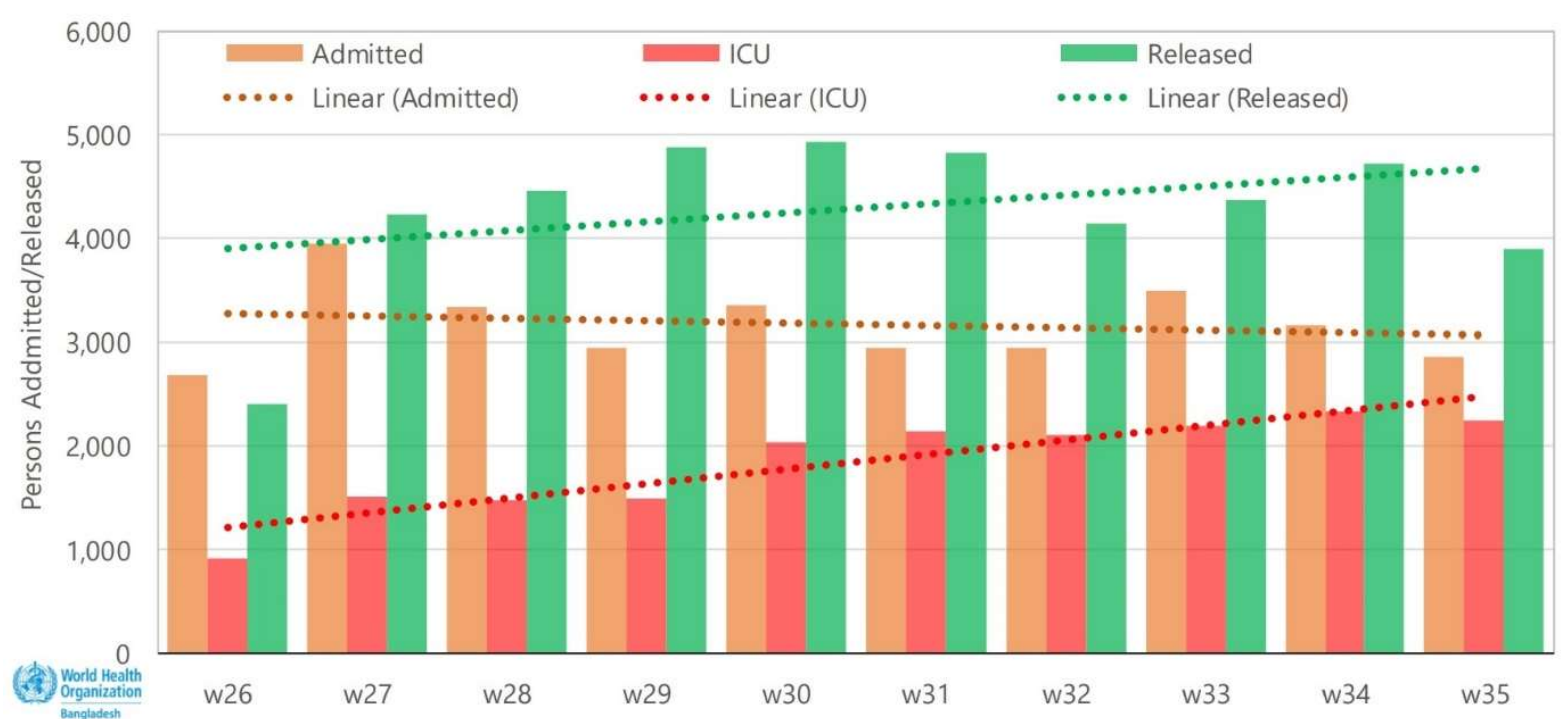

Figure 2. Number of cases admitted, released and taken to ICU in the designated hospital from 24 June to 31 August, 2020 [12]

As of 10 August 2020, the case doubling time in Bangladesh has showed 13.5 days. Available data showed how quickly the number of confirmed cases increased in Bangladesh and some countries in South-East Asia regions: Bangladesh, India, Indonesia, Thailand, Malaysia and Sri Lanka [13].

\section{Materials and Methods}

This study was carried out to find out hospital experiences and impact of COVID-19 in child health in Bangladesh. Three tertiary care hospitals of Bangladesh dealing majority of COVID-19 infected children were selected. Data were collected up to 9 September, 2020 from hospital records from Dhaka Shishu (Children) Hospital, Dhaka Medical College Hospital (up to 5 August, 2020) and Mugda Medical College Hospital. As COVID-19 outbreak also adversely affecting different services among the children of Bangladesh, review was done to evaluate essential health delivery services especially routine immunization.

\section{COVID-19 situation among children in Bangladesh with hospital experience}

So far among the confirmed COVID-19 cases 3\% belongs to age $<10$ years and $7 \%$ belongs to age 11-20 years. Among the confirmed COVID-19 cases $0.82 \%$ deaths belongs to age $<10$ years and $1.49 \%$ deaths belongs to age 11-20 years [8]. Though majority of the cases were mild or moderate in nature but many of them required hospital admission and unfortunately 54 children with COVID-19 infection died [8].

First dedicated Child Corona Unit has been established in Dhaka Medical College Hospital on 10 May, 2020. They have treated 163 cases till 20 July, 2020. Among their admitted cases males were $60.7 \%$ and females were $39.3 \% ; 17.8 \%$ were below 1 year, 28.2\% were between 1 year to 5 years, $21.5 \%$ were 6 years to 10 years and $32.5 \%$ were above 10 years age group. Regarding disease severity, $32.5 \%$ cases were admitted with moderate severity, $38.6 \%$ with severe and $22.1 \%$ cases were critical. Mortality was $5.5 \%$ among the admitted cases in Child Corona Unit of Dhaka Medical College Hospital (Table 1).

Dhaka Shishu (Children) Hospital which is the largest paediatric hospital in Bangladesh also treating COVID-19 cases though initially there was no COVID-19 unit. From 13 July, 2020 they have started there COVID-19 unit dedicated for 
children. Total 228 children were treated in Dhaka Shishu (Children) Hospital till 9 September, 2020 among them male $59.2 \%$ and female $40.8 \%$. They experienced large number of neonate with COVID-19 (14\%), 30.3\% were between 1 month to 12 months, $29.4 \%$ between 1 year to 5 year, $18.4 \%$ between 5 to 10 years and $7.9 \%$ in $>10$ years age group. Regarding disease severity $48.24 \%$ cases were admitted with mild to moderate severity, $35.09 \%$ with severe and $13.16 \%$ cases were critical. Mortality was $3.51 \%$ among the admitted cases (Table 1). Dhaka Shishu (Children) Hospital found many neonate with COVID-19 who did not presented with usual symptoms rather presented with other neonatal medical and surgical problems. They admitted in general ward, surgical ward and cabin but only few were found from neonatal ward and NICU.

Mugda Medical College treated COVID-19 cases along with paediatric cases as it is a dedicated COVID hospital. They have treated 31 children till 9 September, 2020. Among their admitted cases male were $61.3 \%$ and female $38.7 \%$; $9.7 \%$ were below 1 year, 35.5\% were between 1 year to 5 year, $22.6 \%$ were 6 years to 10 years and $32.2 \%$ were above 10 years age group. Regarding disease severity $58.1 \%$ cases were admitted with moderate severity, $25.8 \%$ with severe and $9.7 \%$ cases were critical. Mortality was $3.2 \%$ among the admitted cases (Table 1). Children with COVID-19 are also managed in other dedicated COVID-19 hospitals.

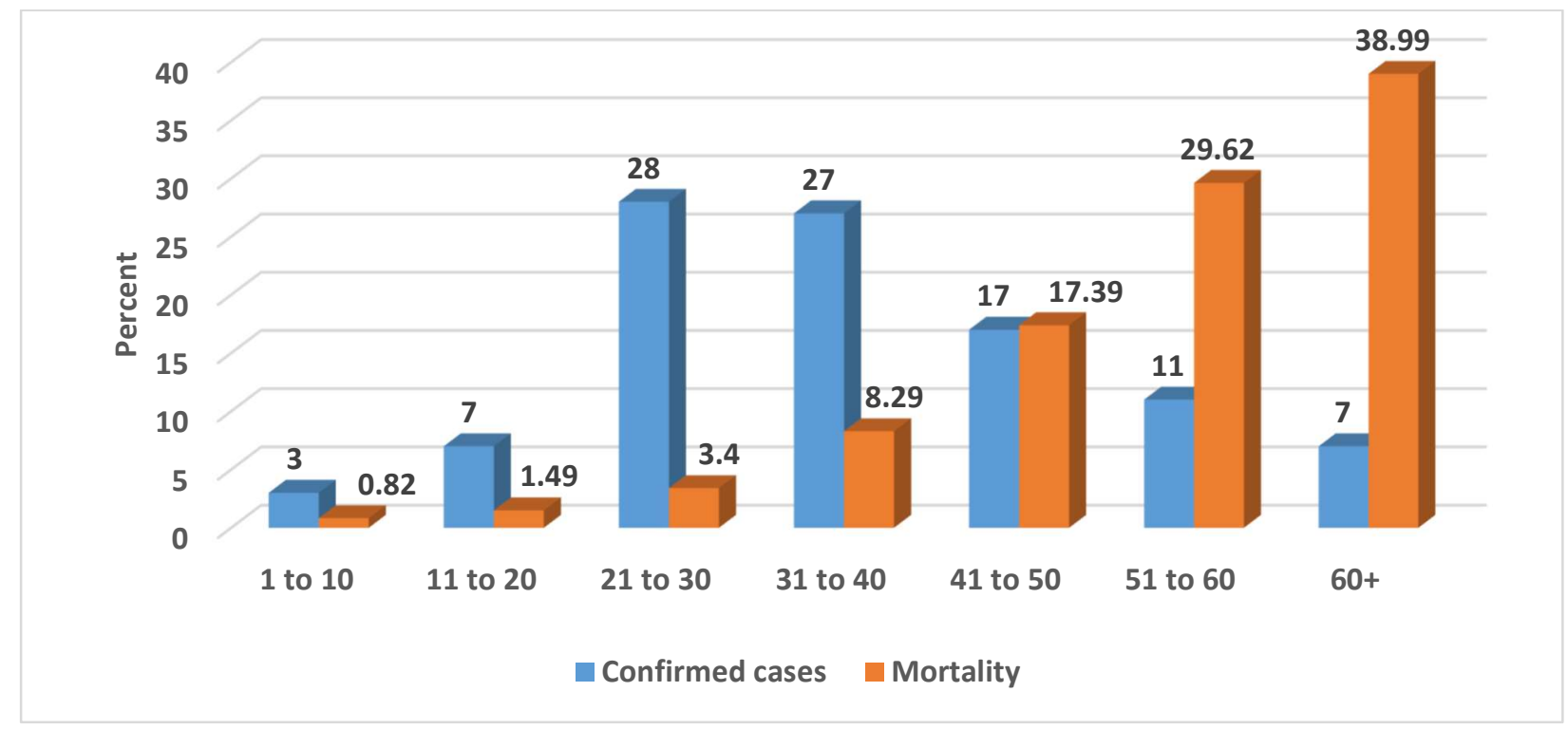

Figure 3. Distribution of COVID-19 confirmed cases and mortality by age group [8] 
Table 1. Distribution of children with COVID-19 admitted in three major hospitals in Bangladesh ( $N=422)$

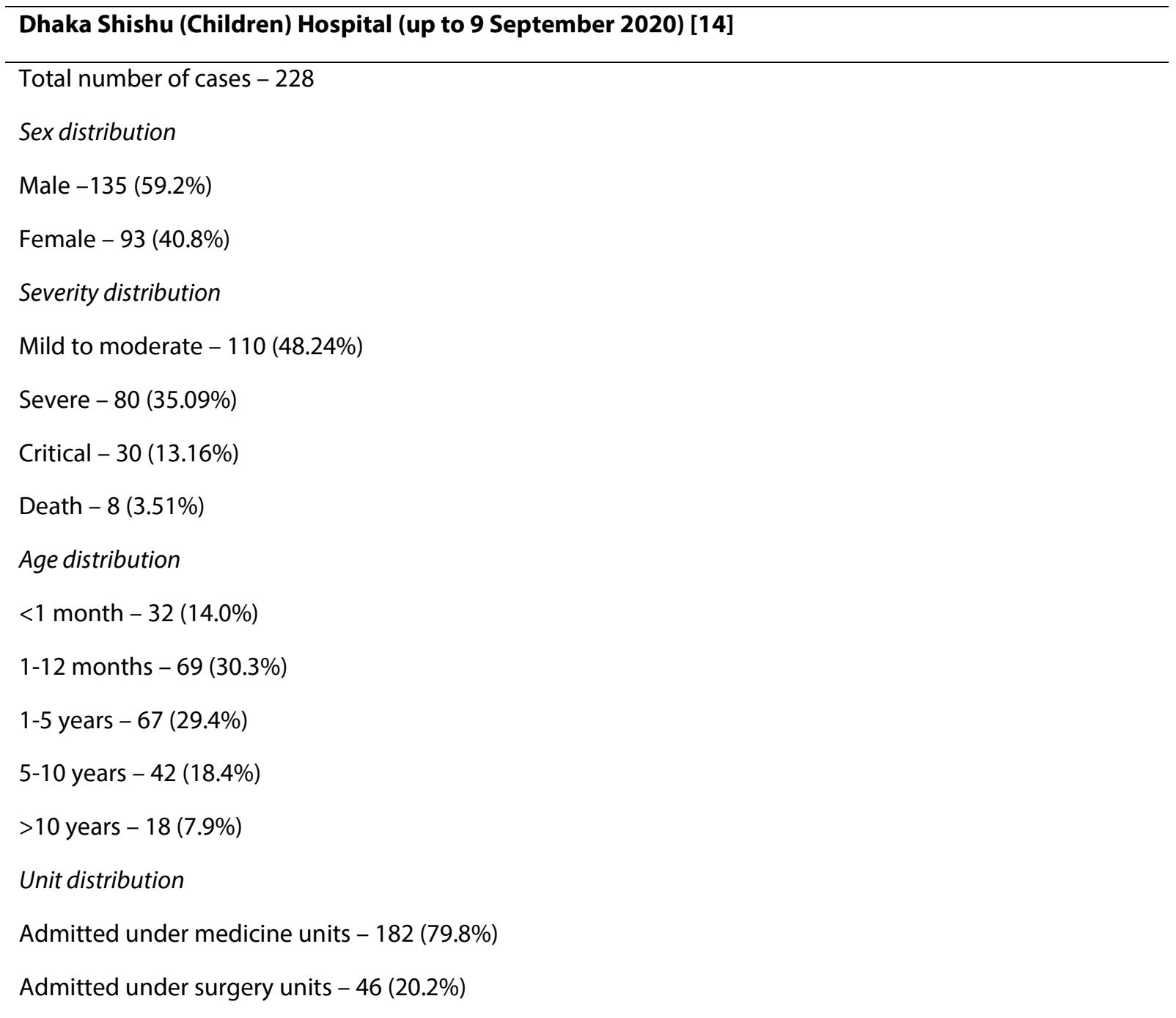

\section{Dhaka Medical College Hospital (up to 5 August, 2020) [15]}

Total number of cases - 163

Sex distribution

Male $-99(60.7 \%)$

Female - $64(39.3 \%)$

Severity distribution

Asymptomatic - 12 (7.4\%)

Moderate - 53 (32.5\%)

Severe - $63(38.6 \%)$

Critical - 35 (21.5\%)

Death - $9(5.5 \%)$

Age distribution

$<1$ year - $29(17.8 \%)$ 


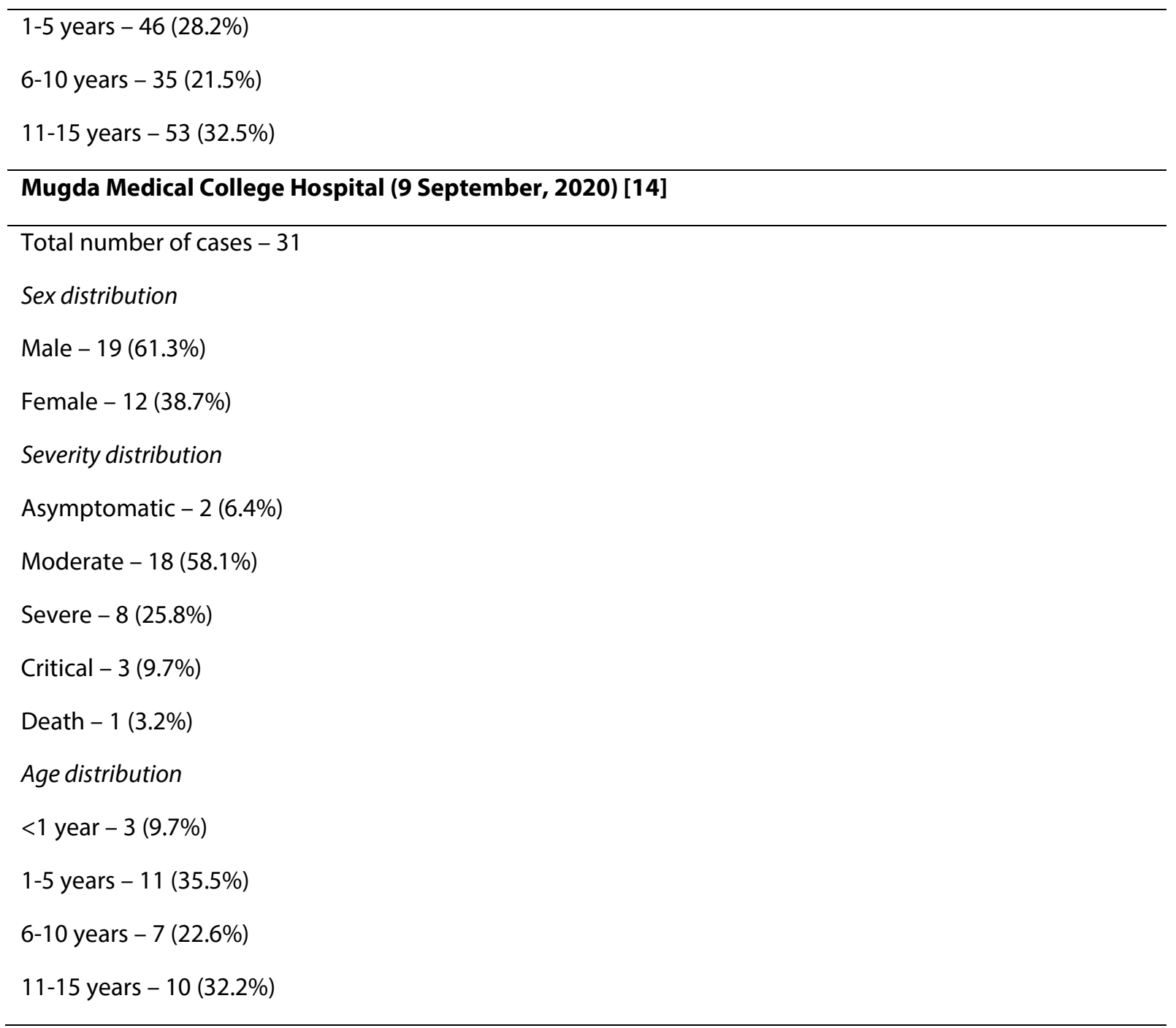

Table 2. Distribution of neonates with COVID-19 admitted in Dhaka Shishu (Children) Hospital up to 19 June, $2020(\mathrm{~N}=15)[16]$

\begin{tabular}{llll}
\hline SI No & Age (in days) & Sex & Primary Diagnosis \\
\hline $\mathbf{1}$ & 2 & Female & Occipital Encephalocele \\
$\mathbf{2}^{*}$ & 20 & Male & Term, AGA with Sepsis \\
$\mathbf{3}^{*}$ & 4 & Female & Term with Perinatal Asphyxia with HIE-II with Pneumonia \\
$\mathbf{4}$ & 22 & Male & Anorectal Malformation \\
$\mathbf{5}$ & 23 & Male & Congenital Heart Disease \\
$\mathbf{6}$ & 5 & Male & Neonatal Jaundice with Sepsis \\
$\mathbf{7}$ & 20 & Female & Pneumonia with Sepsis \\
$\mathbf{8}$ & 1 & Male & Ruptured Lumbo-sacral Meningomyelocele \\
$\mathbf{9}$ & 15 & Male & Posterior Urethral Valve
\end{tabular}




$\begin{array}{llll}10 & 8 & \text { Male } & \text { AKI } \\ 11 & 22 & \text { Male } & \text { Perinatal Asphyxia with HIE-II with Sepsis } \\ 12 * & 6 & \text { Female } & \text { Term, IUGR with Perinatal Asphyxia with HIE-II with Sepsis } \\ 13 & 20 & \text { Male } & \text { Pneumonia with Congenital Heart Disease } \\ 14 & 3 & \text { Male } & \text { Anorectal Malformation with Sepsis } \\ 1 \mathbf{1 5}^{*} & 8 & \text { Female } & \text { Term, AGA with Sepsis }\end{array}$

${ }^{*}$ Directly admitted in NICU

\section{Reduction in child health services in Bangladesh}

Health services for children has decreased significantly due to the COVID-19 pandemic. COVID-19 outbreak will adversely affect the condition of children, particularly in the lives of most vulnerable children. This includes disruption to their healthcare, nutrition, protection, education and overall mental wellbeing including social interaction with friends, peers, family members and caregivers, family planning, antenatal and postnatal care, child delivery, immunization and preventive and curative services. The uptake of maternal and newborn health services have decreased, approximately by 19 percent. In addition, key maternal health services such as antenatal care visits and postnatal check-ups in health facilities have decreased substantially, and deliveries in facilities have decreased by 21 percent for the period of January to March 2020 compared to OctoberDecember 2019 [17].

Critical health services for under-five children has decreased significantly due to the COVID-19 pandemic. The service utilization for children under 5 years of age in March 2020 was down 25 per cent compared to March 2019. A large number of children could die from preventable and treatable conditions if the pandemic leads to substantial reductions in health service coverage. Based on the worst of three scenarios in 118 low- and middle-income countries, the analysis estimates by researchers from the Johns Hopkins Bloomberg School of Public Health, published in The Lancet Global Health Journal warned that an additional 1.2 million under-five deaths could occur in just six months, due to reduction in routine health service coverage levels and an increase in child wasting. These potential child deaths will be in addition to the 2.5 million children who already die before their 5 th birthday every six months, threatening to reverse nearly a decade of progress on ending preventable under-five mortality [18]. Reduction of health services could cause death of over 28,000 children under the age of 5 years in the next 6 months as an indirect result of coronavirus pandemic [18]. The greatest number of additional child deaths will be due to an increase in wasting prevalence among children, which includes the potential impact beyond the health system, and reduction in treatment of neonatal sepsis and pneumonia.

\section{Breast feeding situation in Bangladesh}

WHO and UNICEF encourage women to continue to breastfeed during the COVID-19 pandemic, even if they have confirmed or suspected COVID19. While researchers continue to test breast milk from mothers with confirmed or suspected COVID-19, current evidence indicate that it is unlikely that COVID-19 would be transmitted through breastfeeding or by giving breast milk that has been expressed by a mother who is confirmed or suspected to have COVID19. However breastfeeding is decreased and Breast-milk substitutes use is increased in Bangladesh [19].

\section{Routine immunization coverage in Bangladesh}

Routine immunizations have been severely disrupted, and parents are increasingly reluctant to take their children to health centres. Though routine immunization sessions continue, many outreach sessions have been suspended and the 
transportation of vaccines remains challenging. National mass vaccination campaigns have been postponed. The postponed measles and rubella campaign targets 34 million children aged from 9 months to 9 years [20]. According to service utilization data from the national Management Information System (MIS), the number of immunization sessions dropped by $18 \%$ in April 2020 and by $22 \%$ in May 2020. Furthermore routine immunization coverage for Penta third dose and Measles and Rubella (MR) first dose of vaccine was almost 50\% lower in April 2020 as compared to the same period in 2019 [21]. Country wide over 380,000 children missed their first dose of MR vaccine and over 360,000 children missed the 3rd dose of pentavalent vaccine between January and May 2020 [22].

The surveillance of measles dropped at the alarming level in April and May, 2020, putting Bangladesh at risk of outbreaks of extremely contagious diseases like measles [23].

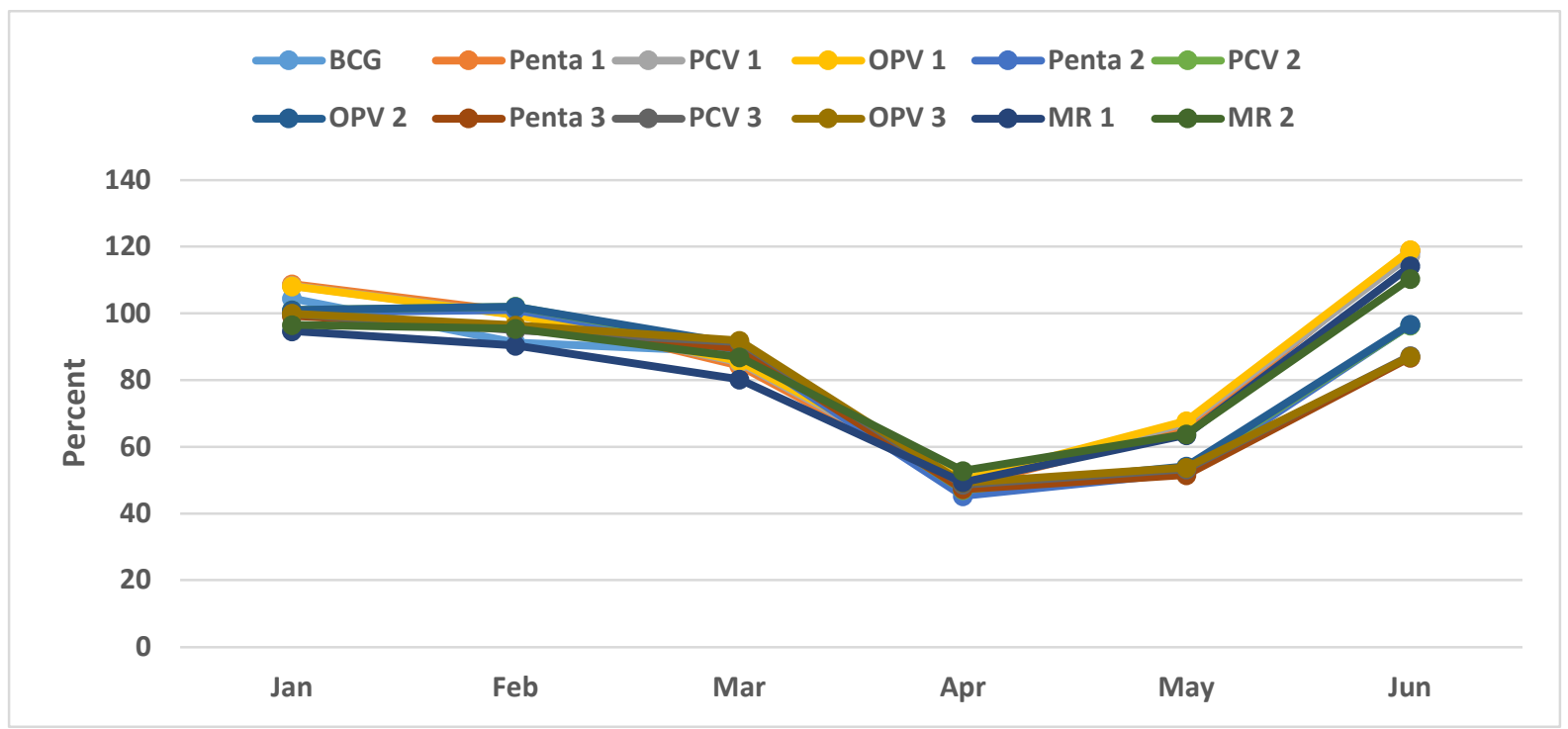

Figure 4. Vaccination coverage in Bangladesh from January to June, 2020 [23]

The DGHS in Bangladesh has issued guidelines to continue routine immunization during COVID-19 pandemic in line with UNICEF and WHO global and regional advisories. Sharp decline from April to May 2020 due to COVID-19 implications are getting back on track due to extra efforts initiated by the Government with WHO support. We must encourage children to receive their routine immunizations with preventive measures including physical distancing, hand washing and face mask. We must make already panicked parents to understand that vaccines are safe, effective and life-saving tools to control and prevent outbreaks of infectious diseases.

\section{Potential impact of COVID-19 on child health in Bangladesh}

All the achievements so far in child health and survival are dependent on the continued provision of essential health services to mothers and children around the world. Bangladesh was successful in achieving the MDG well ahead of scheduled target and proud for being able to lower the newborn, infant and under five mortality appreciably than its neighbourhood.

Experience from the past epidemics like the 2014 West Africa Ebola outbreak and SARS has shown that indirect effects of an outbreak-e.g. medical supply including vaccination chain disruptions, declining of health care services delivery and utilization as well as need of increased healthcare resource and personnel reallocation might be severe, sometimes outpacing the direct impact of the outbreak itself. Moreover, many of these indirect mortality effects may not be apparent for some time after the pandemic recedes and may even reverberate for an extended period following the pandemic. In parts of West Africa, for example, measles deaths among children increased dramatically following the Ebola outbreak as immunizations were curtailed amid the epidemic [24]. 
Reduction in routine immunization coverage, means that many children will be unvaccinated or under-vaccinated, putting their lives at risk of vaccine preventable diseases. Reduction in routine immunization coverage putting millions of children - in rich and poor countries alike - at risk of diseases like diphtheria, measles and polio [25]. Its postulated, post COVID-19 pandemic, many children could die from preventable causes over the next six months. According to a UNICEF analysis, about 77 percent of children under the age of 18 worldwide are living in one of 132 countries with movement restrictions and lockdown. These are creating the household income loss, poverty, hunger and disruptions to care-seeking and preventative interventions like vaccination are also substantial and widespread [17].

The COVID-19 pandemic threatens to disrupt the provision of essential services due to barriers to the supply and demand for services. Mathematical models indicate that large service disruptions in Bangladesh have the potential to leave 1,654,500 children without oral antibiotics for pneumonia, 3,673,600 children without DPT vaccinations, 386,500 women without access to facility-based deliveries, and 5,932,000 fewer women receiving family planning services. As a result of disruptions in all essential services, child mortality in Bangladesh could increase by 37 percent and maternal mortality by 19 percent over the next year [26].

\section{Conclusion}

Pediatric patients are on the rise and unfortunately we noticed large number of hospital admission and some casualties already. Comparing to adults, so far the direct effects of COVID-19 on children and adolescent appears not significant. However, the indirect effect could be horrifying. Essential health care services should be preserved to prevent avoidable losses of child lives during the COVID-19 pandemic and to protect progress in reducing child mortality achieved over recent years.

\section{References}

[1] Huang C, Wang Y, Li X, Ren L, Zhao J, Hu Y, et al. Clinical features of patients infected with 2019 novel coronavirus in Wuhan, China. Lancet. 2020 Feb;395(10223):497-506.

[2] Parry J. China coronavirus: cases surge as official admits human to human transmission. BMJ.

2020;368:m236. doi: https://doi.org/10.1136/ bmj.m236.

[3] Cheng VCC, Wong SC, To KKW, Ho PL, Yuen KY. Preparedness and proactive infection control measures against the emerging Wuhan coronavirus pneumonia in China. (Acccess Published January) J Hosp Infect. 2020 Mar;104(3):254-5.

[4] Zhu N, Zhang D, Wang W, Li X, Song J, Zhao $X$, et al. A novel coronavirus from patients with pneumonia in China, 2019. N Engl J Med. 2020 Feb;382:727-3..

[5] World Health Organization. WHO Timeline COVID-19. Available from: https://www.who.int/newsroom/detail/27.04.2020-who-timeline-covid19. Date accessed: May 31, 2020.

[6] Chen N, Zhou M, Dong X, Qu J, Gong F, Han $Y$, et al. Epidemiological and clinical characteristics of 99 cases of 2019 novel coronavirus pneumonia in Wuhan, China: a descriptive study. Lancet. 2020 Feb;395(10223):507-3.

[7] Wu Z, McGoogan JM. Characteristics of and important lessons from the coronavirus disease 2019 (COVID-19) outbreak in China: summary of a report of 72314 cases from the Chinese Center for Disease Control and Prevention. JAMA. 2020 Feb;323(13):1239-2.

[8] Bangladesh Covid-19 Update. Institute of Epidemiology, Disease Control and Research (IEDCR). Available from https://www.iedcr.gov.bd. Accessed on 10.9.2020.

[9] Dong Y, Mo X, Hu Y, Qi X, Jiang F, Jiang Z, et al. Epidemiological characteristics of 2143 pediatric patients with 2019 coronavirus disease in China. Pediatrics.2020; doi: 10.1542/peds.2020-0702.

[10] Lu X, Zhang L, Du H, Zang J, Li Y, Qu J, et al. SARS-CoV-2 infection in children. $N$ Engl J Med. 2020 Apr; 382:1663-5.

[11] Bangladesh COVID-19 situation reports. World Health Organization. Situation Report 28. Available from 
https://www.who.int/docs/defaultsource/searo/bangladesh/covid-19-whobangladesh-situation-reports/who-covid-19update-28-20200907.pdf?sfvrsn=108ef905_2. Date accessed: September 6, 2020.

[12] Bangladesh COVID-19 situation reports. World Health Organization. Situation Report 27. Available from https://www.who.int/docs/defaultsource/searo/bangladesh/covid-19-whobangladesh-situation-reports/who-covid-19update-27-20200831.pdf?sfvrsn=34e71f15_2. Date accessed: September 6, 2020.

[13] Bangladesh COVID-19 situation reports. World Health Organization. Situation Report 24. Available from https://www.who.int/docs/defaultsource/searo/bangladesh/covid-19-whobangladesh-situation-reports/who-covid-19update-24-

20200810.pdf?sfvrsn=12e69060_2. Date accessed: September 6, 2020.

[14] Hussain M. COVID-19 among children and health care providers: Experience of Dhaka Shishu Hospital. Presented at Live Webinar on COVID19 and vaccine updates. Organized by Bangladesh Paediatric Association on 10 September, 2020.

[15] Farzana F. COVID-19 in children: Experience of Child Corona Unit of Dhaka Medical College. Presented at Live Webinar on COVID-19 in children: Sharing experiences. Organized by Child Corona Awareness on 6 August, 2020.

[16] Shirin M. Management of neonate during COVID-19 pandemic. Presented at Live Webinar on Management of neonate during COVID-19 pandemic. Organized by Bangladesh Neonatal Forum on 20 June, 2020.

[17] UNICEF. As covid-19 devastates already fragile health system, over 6000 additional children under 5 could die a day, without urgent action. Available from https://www.unicef.org/bangladesh/en/press -releases/covid-19-devastates-already-fragilehealth-systems. Accessed on 3.07.2020.

[18] COVID-19: Over 28,000 children could die in 6 months without urgent action. https://unb.com.bd/category/Bangladesh/co vid-19-over-28000-children-could-die-in-6months-without-urgent-action/51543. Accessed on 28.06.2020.
[19] Countries failing to stop harmful marketing of breast-milk substitutes, warn WHO and UNICEFhttps://www.unicef.org/bangladesh/e $\mathrm{n}$ /press-releases/countries-failing-stopharmful-marketing-breast-milk-substituteswarn-who-and-unicef. Accessed on 28.06.2020.

[20] Disruption of child vaccination in South Asia poses an urgent threat to children's health UNICEF. Available from https://www.unicef.org/bangladesh/en/press -releases/disruption-child-vaccination-southasia-poses-urgent-threat-childrens-healthunicef. Accessed on 28.06.2020.

[21] Global Immunization News (GIN). Available at https://www.who.int/immunization/GIN_July 2020.pdf?ua=1.

[22] Routine Immunization in Bangladesh set to get back on track amidst COVID-19 pandemic and massive flooding. Available at https://www.who.int/bangladesh/news/detai l/31-08-2020-routine-immunization-inbangladesh-set-to-get-back-on-track-amidstcovid-19-pandemic-and-massive-flooding

[23] Mowla G. Presented at Live Webinar on COVID-19 in children: Sharing experiences. Organized by Bangladesh Society for Pediatric Infectious Disease on 6 June, 2020.

[24] Child mortality and COVID-19. Available from: https://data.unicef.org/topic/childsurvival/covid-19/. Accessed on 26.07.2020.

[25] At least 80 million children under one at risk of diseases such as diphtheria, measles and polio as COVID-19 disrupts routine vaccination efforts, warn Gavi, WHO and UNICEF. Available from: https://www.who.int/news-room/detail/2205-2020-at-least-80-million-children-underone-at-risk-of-diseases-such-as-diphtheriameasles-and-polio-as-covid-19-disruptsroutine-vaccination-efforts-warn-gavi-whoand-unicef. Accessed on 26.07.2020.

[26] Preserve essential health services during the COVID-19 pandemic: Bangladesh. Available from: https:www.globalfinancingfacility.org/sites/g ff_new/files/documents/Bangladesh-CovidBrief_GFF.pdf. Accessed on: 26.07.2020. 